\title{
Antibiotics in COPD exacerbations: practice and evidence
}

Clinical practice should be directed by scientific evidence in this era of evidencebased medicine. It might then appear curious that paradoxes between practice and the evidence can still occur. Take the example of the use of antibiotics in exacerbations of chronic obstructive pulmonary disease (COPD). A recent systematic review of placebo-controlled antibiotic trials in acute exacerbations of COPD (AECOPD) concluded that they did not support the use of antibiotics for mild or moderate exacerbations [1]. Conversely, the report of the UK national COPD audit of 9,716 adults admitted with this diagnosis in 2008 to 177 hospitals recorded antibiotic treatment in $81 \%$ [2]. So why is there this paradox?

First there is history. The identification of bacteria, then the discovery of antibiotics, taken with the occurrence of purulent sputum in AECOPD and the microscopic identification of bacteria in these samples led to the early adoption of antibiotics as one of the pillars of AECOPD management. All of this occurred when other causes (for example viruses [3]) for COPD exacerbation could not be reliably identified. In addition, antibiotics were perceived to be overwhelmingly beneficial without significant side-effects at a time when objective assessment of scientific evidence was a fledgling science. This is despite one of the earliest placebo-controlled studies being conducted in 1957 that found no benefit from antibiotics compared with placebo [4].

A number of similar studies followed, and one issue with the evidence is that most of these trials are old from today's standpoint. For this reason they can be criticised on their methodological robustness, the use of antibiotics that may no longer be considered to be standard (e.g. sulphonamides), poor profiling of patient characteristics, lack of control for other interventions now known to influence outcome and weak end- points.

A number of meta-analyses and systematic reviews have preceded the previously mentioned study [1] and have come to rather different conclusions. One of the earliest concluded that there was a small but statistically significant improvement due to antibiotic therapy [5]. The authors suggested that this may be clinically significant - not an overwhelming endorsement! The 2006 Cochrane systematic review supported the use of antibiotics for patients with COPD exacerbations with increased cough and sputum purulence who are moderately or severely ill [6]. However, the authors correctly acknowledged the limitations of this

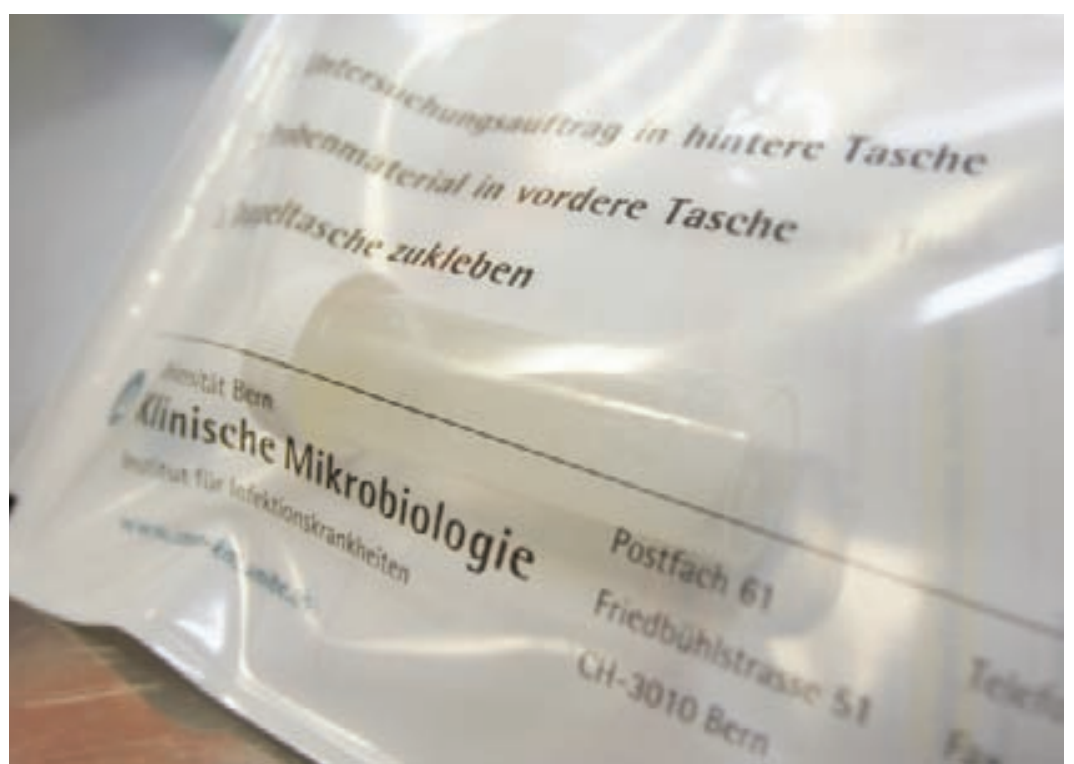


review, which were largely due to the methodology of these older trials. One study, that showed the largest benefit from antibiotics, had a disproportionate influence on the conclusions of the Cochrane review [7]. This small study was conducted on an intensive care unit without the use of many usual additional interventions such as steroid therapy and its results cannot therefore be generalised to hospital admissions or outpatients with AECOPD. The evidence base is therefore flawed, but it does appear likely that there may be a subgroup who might benefit, even if the overall conclusion is of a small or even no benefit from antibiotics.

This was explored in one sentinel study [8] and repeated in a separate Italian study [9]. The results of these 20-year-old studies remain the basis for current antibiotic practice in AECOPD. In this study, a clear benefit from antibiotics was only found in those with Type 1 exacerbations (all three of increased sputum purulence, sputum volume and breathlessness), with no benefit in Type 3 (only one of the three features) and minimal benefit in Type 2 (two of the three features). However, even in Type 1 exacerbations 43\% responded to placebo, albeit with a higher subsequent deterioration rate. While this clinical rule can be a basis for clinical practice it remains far from perfect as patients who will not benefit from antibiotic exposure are still unnecessarily receiving antibiotics. This we now know is harmful both to the individual and the population and should be avoided if possible.

Do newer antibiotics make a difference? Well probably not. In a study of one of the newer fluoroquinolones, a difference in bacteriological outcome in favour of the fluoroquinolone was found, but this did not translate into a clinical benefit - at least not in clinical recovery from the exacerbation [10]. Interestingly, this study did find an association with fluoroquinolone use and a delay in the onset of subsequent exacerbations, so maybe we have been studying the wrong end-points? One older study found that short-term mortality was reduced by pre-hospital antibiotic therapy [11] and another that relapse rates were reduced in antibiotic-treated patients regardless of type [12] and this has been reproduced in a more recent study based on general practice [13]. These findings remain associations since antibiotic use may simply be a marker of some other aspect of beneficial care. Another fluoroquinolone study did not find this difference [14].

Maybe different antibiotics are required by different patients? Studies have shown that the bacteriology of the airways may differ according to lung function, with Gram-negative organisms such as Pseudomonas aeruginosa being more common in those with poorer lung function $[15,16]$. However, this has not been reproduced in other populations [17].

Maybe the Holy Grail of giving antibiotics only to those who will benefit is not achievable using simple clinical markers. Two studies in the same setting have suggested biomarkers, specifically procalcitonin, can be used to direct antibiotic therapy in AECOPD $[18,19]$. Larger studies are required to ensure that those who do not receive antibiotics directed in this way are not at a disadvantage and the results need to be reproduced in other settings, but this may be the way forward.

Ultimately the paradox is driven by inadequate evidence. Evidence can only guide practice when it is robust, unequivocal and generalisable and the data on antibiotics in AECOPD fulfil none of these requirements as yet. Undoubtedly we know more than we did but we are not there yet!

\section{References}

1. Puhan MA, Vollenweider D, Steurer J, Bossuyt PM, Ter RG. Where is the supporting evidence for treating mild to moderate chronic obstructive pulmonary disease exacerbations with antibiotics? A systematic review. BMC Med 2008; 6: 28 .

2. Royal College of Physicians of London, British Thoracic Society, British Lung Foundation. Report of the National Chronic Obstructive Pulmonary Disease Audit 2008: Clinical Audit of COPD Exacerbations Admitted to Acute NHS Units Across the UK. www.rcplondon.ac.uk/clinical-standards/ceeu/Current-work/ncrop/Documents/Report-ofThe-National-COPD-Audit-2008-resources-and-organisation-of-care-in-acute-NHS-units-across-the-UK.pdf Date created: September 2008.

3. Seemungal T, Harper-Owen R, Bhowmik A, et al. Respiratory viruses, symptoms, and inflammatory markers in acute exacerbations and stable chronic obstructive pulmonary disease. Am J Respir Crit Care Med 2001; 164: 1618-1623.

4. Elmes PC, Fletcher CM, Dutton AA. Prophylactic use of oxytetracycline for exacerbations of chronic bronchitis. BMJ 1957; $2: 1272-1275$.

5. Saint S, Bent S, Vittinghoff E, Grady D. Antibiotics in chronic obstructive pulmonary disease exacerbations. JAMA 1995; 273: 957-960. 
6. Ram FS, Rodriguez-Roisin R, Granados-Navarrete A, Garcia-Aymerich J, Barnes NC. Antibiotics for exacerbations of chronic obstructive pulmonary disease. Cochrane Database Syst Rev 2006; 2: CD004403.

7. Nouira S, Marghli S, Belghith M, Besbes L, Elatrous S, Abroug F. Once daily oral ofloxacin in chronic obstructive pulmonary disease exacerbation requiring mechanical ventilation: a randomised placebo-controlled trial. Lancet 2001; 358: 2020-2025.

8. Anthonisen NR, Manfreda J, Warren CPW, Hershfield ES, Harding GKM, Nelson NA. Antibiotic therapy in exacerbations of chronic obstructive pulmonary disease. Ann Int Med 1987; 106: 196-204.

9. Allegra L, Blasi F, de Bernardi B, Cosentini R, Tarsia P. Antibiotic treatment and baseline severity of disease in acute exacerbations of chronic bronchitis: a re-evaluation of previously published data of a placebo-controlled randomized study. Pulm Pharmacol Ther 2001; 14: 149-155.

10. Wilson R, Allegra $\mathrm{L}$, Huchon $\mathrm{G}$, et al. Short-term and long-term outcomes of moxifloxacin compared to standard antibiotic treatment in acute exacerbations of chronic bronchitis. Chest 2004; 125: 953-964.

11. Sin DD, Tu JV. Outpatient antibiotic therapy and short term mortality in elderly patients with chronic obstructive pulmonary disease. Can Respir J 2000; 7: 466-471.

12. Adams SG, Melo J, Luther M, Anzueto A. Antibiotics are associated with lower relapse rates in outpatients with acute exacerbations of COPD. Chest 2000; 117: 1345-1352.

13. Roede BM, Bresser P, Prins JM, Schellevis F, Verheij TJ, Bindels PJ. Reduced risk of next exacerbation and mortality associated with antibiotic use in COPD. Eur Respir J 2009; 33: 282-288.

14. Lode H, Eller J, Linnhoff A, Ioanas M. Levofloxacin versus clarithromycin in COPD exacerbation: focus on exacerbation-free interval. Eur Respir J 2004; 24: 947-953.

15. Eller J, Ede A, Schaberg T, Niederman MS, Mauch H, Lode H. Infective exacerbations of chronic bronchitis. Relation between bacteriologic etiology and lung function. Chest 1998; 113: 1542-1548.

16. Miravitlles M, Espinosa C, Fernandez-Laso E, Martos JA, Maldonado JA, Gallego M. Relationship between bacterial flora in sputum and functional impairment in patients with acute exacerbations of COPD. Study Group of Bacterial Infection in COPD. Chest 1999; 116: 40-46.

17. Groenewegen $\mathrm{KH}$, Wouters EF. Bacterial infections in patients requiring admission for an acute exacerbation of COPD: a 1-year prospective study. Respir Med 2003; 97: 770-777.

18. Christ-Crain M, Jaccard-Stolz D, Bingisser R, et al. Effect of procalcitonin-guided treatment on antibiotic use and outcome in lower respiratory tract infections: cluster-randomised, single-blinded intervention trial. Lancet 2004; 363: 600-607.

19. Stolz D, Christ-Crain M, Bingisser R, et al. Antibiotic treatment of exacerbations of COPD: a randomized, controlled trial comparing procalcitonin-guidance with standard therapy. Chest 2007; 131: 9-19.

\section{Ask the Expert - Smoking cessation strategies}

In the next issue of Breathe, to be published in September at the European Respiratory Society's Congress, Professor Jacques Prignot of the Université Catholique de Louvain in Belgium will answer readers' questions about smoking cessation strategies - from setting up clinics to be benefits and drawbacks of different therapies and strategies and the effects of tobacco. Professor Prignot was until very recently programme secretary of the International Union Against Tuberculosis and Lung Disease's Tobacco Control Section, and has written extensively on the subject of tobacco control, among many other topics.

Professor Prignot cannot enter into direct correspondence with readers or answer questions about specific cases. Questions with wider relevance to common problems are most likely to be answered. Please send your questions to breathe@ersj.org.uk by Monday, June 29, 2009. 